\title{
For the initiation of Asia-Pacific Journal of Regional Science: why it is potentially so important
}

\author{
Kingsley E. Haynes ${ }^{1}$
}

Published online: 25 January 2017

(C) The Japan Section of the Regional Science Association International 2017

It is with great support that I write this note congratulating the editors and publishers of this new journal! The Asia-Pacific Journal of Regional Science addresses one the most important regions of the world. The region as a whole contains two thirds of the world population and over half the world's economy. It is also the most rapidly growing world region with growth rates in the 5-7\% range, which is much higher than other regions.

Its international and inter-regional trade is the envy of the rest of the world. Its set of highly productive national economies are supported by one of the most complex and efficient international logistical supply chains in the world. This makes international and intra-regional trade of central importance. This complex logistical supply chain interaction and the trade that accompanies it is sometimes called the "spaghetti bowl" but would be more appropriately termed the "noodle bowl". It exists due in part to the inter-regional diversity within this mega-region with two of the largest continental national economies (China and India) and the two largest maritime economies (Indonesia and the Philippines) in the world. The regions income variation is huge ranging from Nepal and Bhutan at one end to Singapore and Japan at the other end. This also reflects both the most sophisticated developed economies such as Japan and Korea and the least developed economies of Myanmar and New Guinea.

The little Asian Tiger economies of Thailand and Korea among others contain some of the most sophisticated human capital available in the world. However, within nation regional variation in differences are incredible. For example, within China it is staggering to compare the Pearl River Delta Region (Shenzhen, Hong Kong, Macau, Zuhai and Guandoug/Guanzou) to the Shanghai-Pudong, and the Beijing-Tianjin Corridor and to understand the most rapidly developed space economies of the twenty-first century. Such impressive development naturally comes with comparisons to the stubbornly less developed China rust belt of the

Kingsley E. Haynes

khaynes@gmu.edu

1 Schar School of Policy and Government, George Mason University, Arlington, VA 22201, USA 
northeast region. Such issues of inter-regional disparity within nations are of great concern in huge national economies such as India and China. Industrial verses agricultural regions and industrially innovative and dynamic service regions are contrasted with culturally and economically deprived regions. This economic diversity can be contrasted with demographic diversity that is equally complex and represents the full range of concerns that such demographics imply worldwide.

Japan and Korea have the fastest aging populations on the planet while China is beginning to show signs of ageing as well. This is in contrast to India, the Philippines and Bangladesh leading the world in some of the highest birth rates. The consequence of these differences for the local economies in supplying food, government services including education and health care and well as social support services is a staggering differential burden. This has important implications for the future development process and for industrial capacity and labor availability to say nothing of entrepreneurship and innovation.

To have a journal looking at this world region to understand its complex interregional economic, social, and political interactions is a critical intellectual challenge. Of course one of the central themes in such an analysis is the impact this region and its sub-regions have on each other and on the outside world. The impact on the local and world environment as the development process pushes forward is of central importance. Pollution issues in rapidly urbanizing centers such as Beijing are exemplary of this problem. The new infrastructure needed to manage the problems of water supply and wastewater management as well as energy supply and transportation vary by region reflecting different problems and solution strategies. What are the implication for high-speed rail in China and China's "One Road-One Belt" Policy on the rest of the region? How will Australia and Indonesia's commodity supply systems affect the region and their full integration into the AsiaPacific complex? Just as China is increasingly seeing the South China Sea as a private China Lake instead of a free maritime causeway, what will be the view of the Pacific as an open maritime system with Canada, Mexico, Central America, Columbia, Ecuador, Peru and Chile (let alone the Western US-California, Oregon and Washington) on one side and Asia on the other. Both sides and their regions are dependent on this water way for transportation, industrial resources and food.

To not have a journal addressing these issues makes us wonder why it has not come about before. However, at least now we will see how analytical methods can be brought to bare on such important problems. Hence, I again congratulate the editors and publishers for taking on this important challenge. I wish them the very best and again enunciate the importance and vital need for their success.

This new title is also the next intellectual step in the expansion of the Regional Science Association International's (RSAI) journal development. The European Regional Science Association (ERSA) recently inaugurated its own journal. The North American region has had its own journals for sometime but the Pacific Regional Science Conference Organization (PRSCO) has never had its own voice. So in a direct way this is a coming of age of a very important part of this international organization and the Asia Pacific Region. I can not think of a better example of intellectual participation and representation of knowledge development and sharing. 